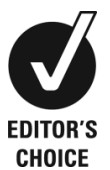

CHOICE

\title{
Intramuscular sinusoidal haemangioma with secondary Masson's phenomenon
}

\author{
Paremala Konda, Radhika M Bavle, Soumya Makarla, Sudhakara Muniswamappa
}

Department of Oral Pathology, Krishnadevaraya College of Dental Sciences, Bangalore, Karnataka, India

\section{Correspondence to}

Dr Soumya Makarla, soumyamakarla@gmail.com

Accepted 5 December 2015

\section{SUMMARY}

Intramuscular haemangiomas (IMHs) are rare benign vascular neoplasms that account for approximately $0.8 \%$ of all haemangiomas. The histology of IMHs can reveal cavernous dilated spaces. We report an interesting case of haemangioma in the deep skeletal muscle of the right labial mucosa in a young man involving the orbicularis oris muscle which showed additional features of sinusoidal arrangement with a secondary Masson's phenomenon.

\section{BACKGROUND}

Haemangiomas are common soft tissue tumours which account for about $7 \%$ of all benign tumours. They occur commonly during infancy and childhood. ${ }^{1}$ Intramuscular location of these lesions is rare and constitutes $<1 \%$ of all haemangiomas. ${ }^{2}$ Approximately $15 \%$ of intramuscular haemangiomas (IMHs) occur in the head and neck area. The masseter and trapezius muscles are most commonly affected (60\%) followed by the periorbital, sternomastoid, temporalis, geniohyoid and medial pterygoid muscles. ${ }^{3}$ Due to their rarity, deep location, intriguing aetiopathogenesis, variable clinical presentation and differences in treatment modality, IMHs require special attention. Sinusoidal haemangiomas, although a distinct subset of cavernous haemangiomas, are rare. Their clinicopathological characteristics are important and need to be recognised to avoid any diagnostic pitfalls. ${ }^{4}$ Masson's tumour, or intravascular papillary endothelial hyperplasia, represents an unusual endothelial proliferation which can occur primarily in a venous channel or secondarily in a vascular anomaly. ${ }^{5}$ It is an important entity which needs to be distinguished from malignancies such as angiosarcoma to avoid radical surgery.

\section{CASE PRESENTATION}

A male student in his early 20s reported to the outpatient department of our hospital with a chief complaint of a solitary painless swelling on the lower right side of the face that had gradually been increasing in size over a period of 4 years. Extraoral examination revealed an ill-defined swelling near the angle of the mouth on the right side measuring approximately $2.0 \times 3.0 \mathrm{~cm}$ and extending $1 \mathrm{~cm}$ above the lower border of the mandible. The swelling was firm to palpate. The overlying skin appeared normal with no rise in the local temperature (figure $1 \mathrm{~A}$ ).

Intraoral examination revealed a solitary illcircumscribed swelling in the right labial mucosa measuring approximately $2.0 \mathrm{~cm} \times 2.5 \mathrm{~cm}$ in diameter, extending in relation to 43 to 44 region, with mild obliteration of the labial vestibule. There was no tenderness on palpation or any signs of discharge. The overlying mucosa appeared stretched but normal. The mucosa over the swelling was slightly blanched with one area showing a slight bluish hue (figure 1B). There was no associated cervical lymphadenopathy. The patient's periodontal status was good with a full complement of permanent teeth.

The lesion was surgically excised under local anaesthesia and submitted with a provisional diagnosis of mucocele for histopathological examination. On macroscopic examination the excised lesion was roughly oval in shape, brown in colour, measuring $1.8 \times 1.0 \mathrm{~cm}$ with an irregular surface and firm consistency (figure 2).
To cite: Konda $P$, Bavle RM, Makarla S, et al. BMJ Case Rep Published online: [please include Day Month Year] doi:10.1136/ bcr-2013-201457

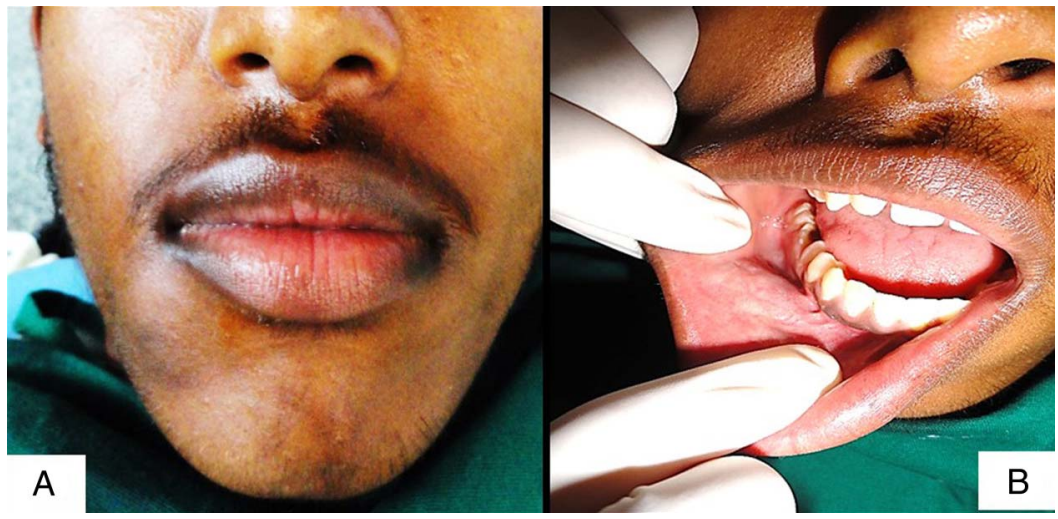

Figure 1 (A) Clinical photograph showing a solitary swelling on the right side below the angle of the mouth. (B) Clinical photograph showing a solitary ill-circumscribed swelling in the left buccal mucosa obliterating the buccal vestibule with an area exhibiting a bluish hue. 


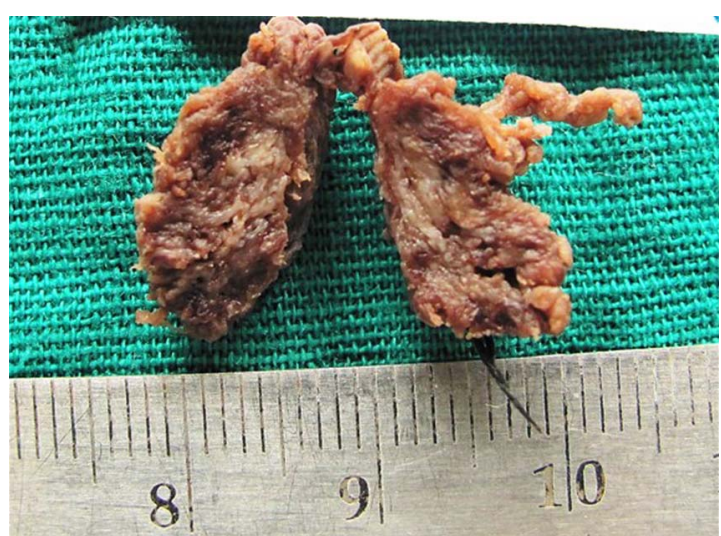

Figure 2 Macroscopic examination of the excised lesion showing an irregular surface of firm consistency and brown in colour.

Histopathological examination of the formalin-fixed, processed and H\&E-stained tissue sections revealed connective tissue stroma containing numerous closely packed enlarged endothelial-lined blood vessels interspersed between the skeletal muscle fibres (figure 3A, B). Vascular spaces were thin-walled, variable in size, dilated with a back-to-back arrangement in a sinusoidal fashion (figure 3C). Few blood vessels were engorged with red blood cells. The endothelial cells were bland with no evidence of pleomorphism or mitosis (figure 3D). Intravascular organising thrombi were evident. Papillary projections into the vascular lumen were present with evidence of Masson's phenomenon (figure 4). Other areas showed abundant endothelial cell proliferations (figure 5). Few skeletal muscle fibres exhibited areas of degeneration.

Immunohistochemical staining with $\mathrm{Ki}-67$ showed positivity in the nuclei of the endothelial cells lining the blood vessels between the skeletal muscle fibres (figure 6), indicating an increase in their mitotic activity.

Based on the above histopathological features, a final diagnosis of intramuscular sinusoidal haemangioma with secondary Masson's phenomenon was made.

\section{INVESTIGATIONS}

A routine complete haemogram including clotting and bleeding time was done prior to the surgery. Diagnosis preoperatively is not straightforward and this condition is mostly recognised only during surgical exploration or on histopathological examination.

\section{DIFFERENTIAL DIAGNOSIS}

IMH can be differentiated from vascular malformations by complete or incomplete lining around the endothelial cells by smooth muscle cells and fibres forming a complete or partially matured wall which is lacking in haemangiomas.

Angiosarcomas can be identified by necrosis, haemorrhage, mitotic figures, nuclear and cellular pleomorphism, all of which are lacking in haemangiomas. Intramuscular lipomas, myxomas and granular cell tumours can be identified by the presence of adipose tissue, myxomatous tissue and granular cell elements in the tissue.

\section{TREATMENT}

A planned incision was made under local anaesthesia. The lesion ruptured while the dissection was being done. Separation of the lesion along with the muscle bands was carried out. The bleeding was arrested with electrocautery and the surgical site was closed with silk sutures (figure 7).
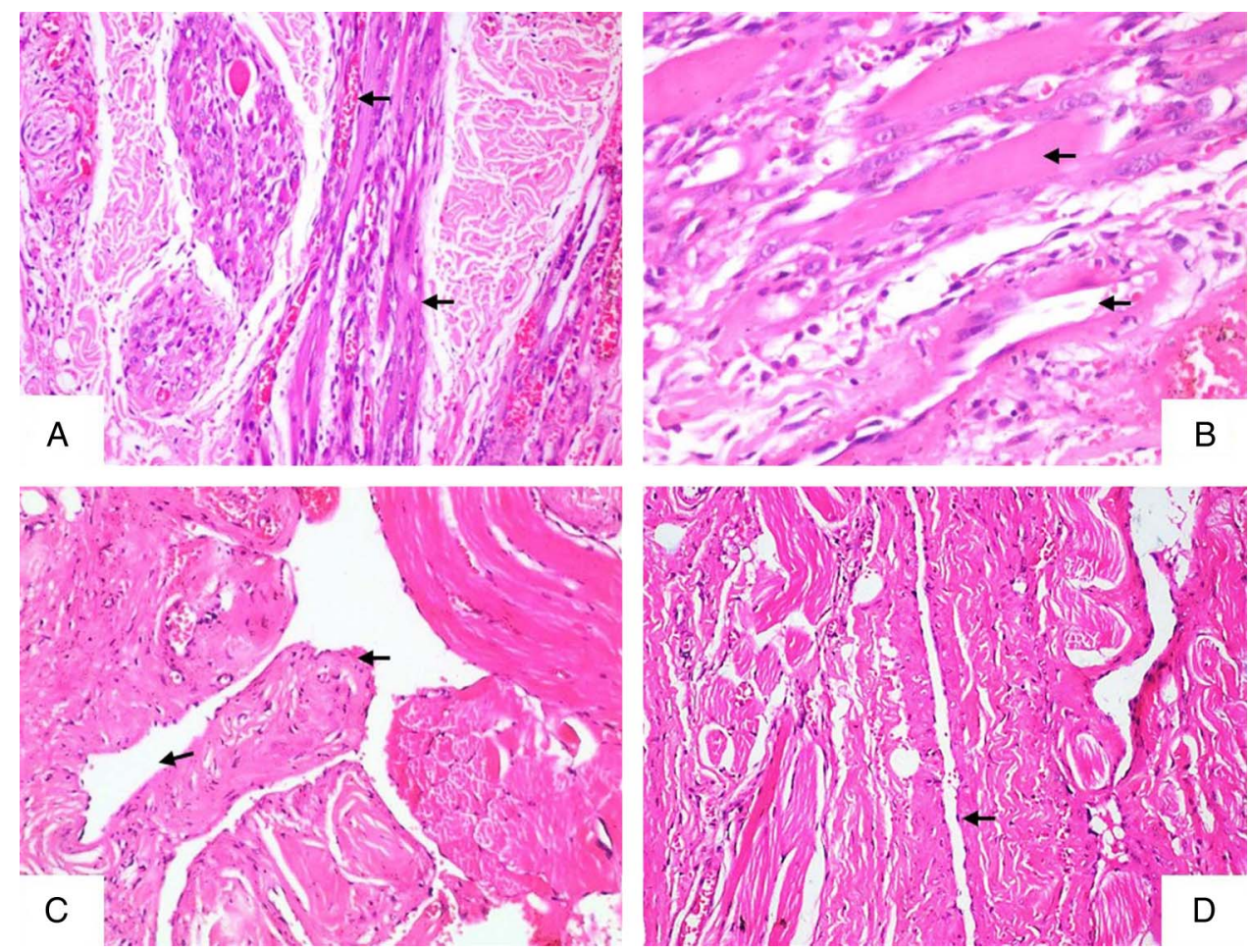

Figure 3 (A) Photomicrograph showing endothelial-lined capillaries engorged with red blood cells between the skeletal muscle bundles (H\&E $\times 100$ ). (B) Photomicrograph showing plump endothelial-lined capillaries between the skeletal muscle bundles (H\&E $\times 200)$. (C) Photomicrograph showing thin-walled dilated vascular spaces with a back-to-back arrangement in a sinusoidal fashion along with a large papillary projection (H\&E $\times 100$ ). (D) Photomicrograph showing bland endothelial cells lining a vascular space with no evidence of pleomorphism (H\&E $\times 100)$. 


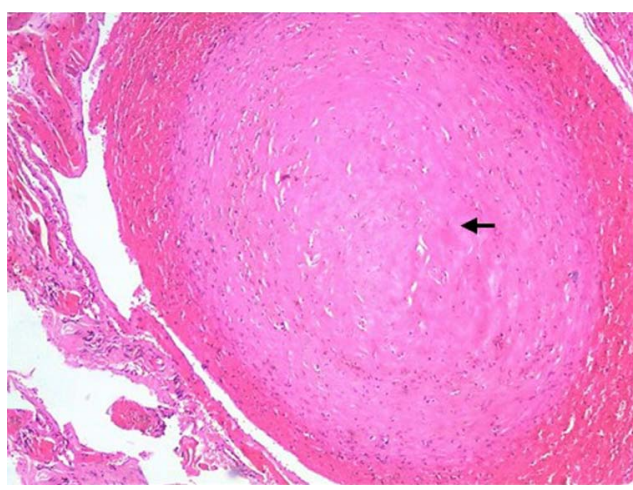

Figure 4 Photograph showing organising thrombus within a vessel together with papillary structures $(\mathrm{H} \& \mathrm{E} \times 40)$.

\section{OUTCOME AND FOLLOW-UP}

The patient has been under regular follow-up every 6 months for 4 years with no signs of recurrence to date.

\section{DISCUSSION}

Haemangiomas comprise $7 \%$ of all benign tumours. ${ }^{1}$ They are benign proliferative vascular tumours characterised by increased endothelial cell turnover. They usually appear after birth, grow rapidly and involute over the years. ${ }^{6}$ They are commonly superficial and are easy to diagnose whereas deep-seated lesions like IMH are uncommon and difficult to diagnose.

IMH was first reported by Lister in $1843 .^{8}$ It is a distinct type of hemangioma occurring within skeletal muscle and making up $<1 \%$ of all hemangiomas. They occur predominantly in the skeletal muscles. ${ }^{9}$ Fifteen per cent of all IMHs occur in the head and neck area with the masseter being the most common muscle to be involved, followed by the trapezius muscle. ${ }^{10}$ The cause of IMH lesions is unknown, although theories of development include trauma and abnormal sequestration of embryonic tissue. ${ }^{11}$ They are non-metastasising benign congenital tumours that remain unrecognised for a long time and may suddenly start growing in the second or third decade of life. ${ }^{12}$ Although IMHs show an equal sex distribution, involvement of the masseter muscle has a definite male predominance. ${ }^{13}$ The common complaint is the presence of a painful, slow growing mass with no aesthetic concerns. ${ }^{14}$ The lesion does not usually show any of the vascular signs such as thrill or skin discolouration that are characteristic of superficial haemangiomas. ${ }^{12}$

The case reported here is in accordance with the previous literature regarding age, gender and clinical symptoms and the

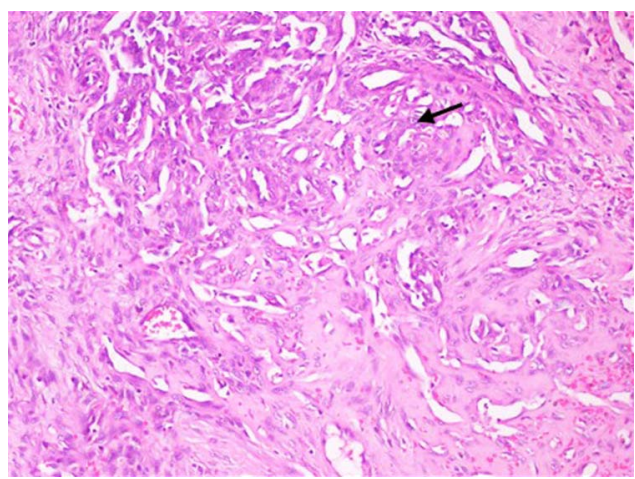

Figure 5 Photomicrograph showing abundant endothelial cell proliferation $(\mathrm{H} \& \mathrm{E} \times 100)$.

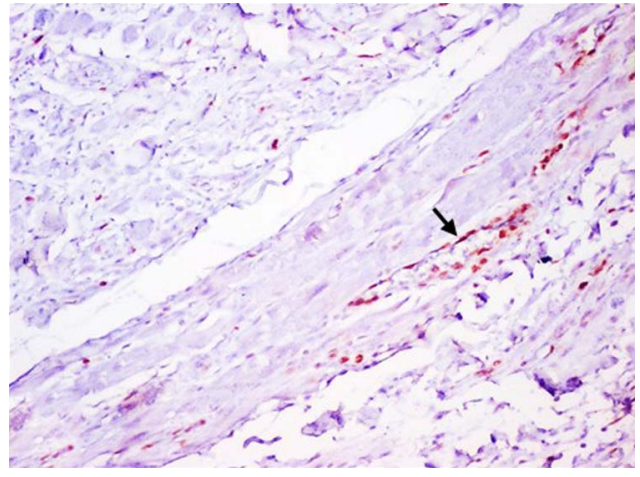

Figure 6 Photomicrograph showing immunopositivity for Ki-67 only to the endothelial cells between the skeletal muscle fibres ( $H \& E \times 200$ ).

skeletal muscle involved is the orbicularis oris. Histologically, the lesion is unencapsulated and has the ability to infiltrate adjacent muscles and consists of proliferation of mesenchymal tissue. The tumour can be classified into three types (capillary, cavernous and mixed) based on the predominant vascular pattern. $^{15}$

Sinusoidal haemangioma is a rare entity and a subset of cavernous haemangioma that has been described by Calonje and Fletcher. ${ }^{16}$ Histologically, it is characterised by thin-walled intercommunicating vascular channels arranged in a sinusoidal pattern. The dilated vessels have a back-to-back arrangement with minimal intervening stroma. A pseudopapillary pattern is evident on cross-section. Immunostaining with Ki-67 showed minimal positivity in the endothelial cells, which suggests that the proliferation rate of this lesion is low and can be distinguished from malignant vascular tumours. ${ }^{17}$

Masson's 'vegetant intravascular hemangioendothelioma' is a lesion which is often confused with angiosarcoma. It was first described by Pierre Masson in 1923. Intravascular papillary endothelial hyperplasia is a reactive condition representing an exuberant organisation and recanalisation of a thrombus. It occurs in three types: (1) pure or primary form which arises de novo in a dilated vascular space; (2) secondary/reactive/mixed form, which is a focal change in a pre-existing vascular lesion

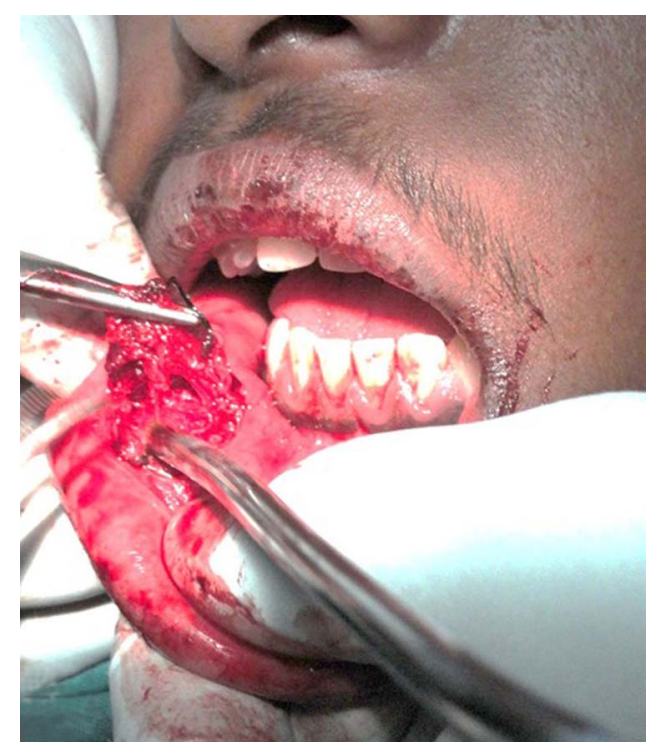

Figure 7 Clinical image showing dissection of the lesion during surgical excision. 
(haemangioma, vascular malformation, pyogenic granuloma); and (3) extravascular rare form, which is due to organisation of haematoma. ${ }^{18}$

The histogenesis of this lesion is obscure, so it represents a lesion of reactive nature rather than a true neoplasm. ${ }^{19}$

It consists of a mass of anastomosing vascular channels with a variable degree of intraluminal papillary projections. The stroma consists of hyalinised eosinophilic non-collagenous material which is non-refractile on polarisation. ${ }^{5}$

Our case is a secondary/reactive form which formed in a preexisting haemangioma as a focal change. There are no reported cases of malignant transformation or metastasis of IMH. The recurrence rate, which is about $50 \%$, is not related to the histological variant or anatomical location of the lesion. ${ }^{11}$

Our patient had an intramuscular variant of haemangioma involving the orbicularis oris which exhibited a sinusoidal pattern on histological examination. The lesion showed thrombus formation, which was resolving, with secondary Masson's phenomenon.

\section{Learning points}

- Intramuscular haemangioma may start in childhood and should be considered in the differential diagnosis of any isolated muscle enlargement. The treatment of choice should be individualised according to the patient's age, symptoms, cosmetic, functional or neurological deficits, depth of invasion and vascular structure of the tumour.

- Sinusoidal haemangiomas are rare and generally require a multidisciplinary approach. Wide excision of the tumour is surgically recommended to prevent relapse and recurrence.

- Masson's phenomenon is clinically important as it presents as a mass which may be histologically mistaken for angiosarcoma. Thus, the pathologist should be aware of this lesion to avoid an incorrect diagnosis and aggressive treatment.

Contributors All the authors contributed equally to the manuscript.
Competing interests None declared.

\section{Patient consent Obtained.}

Provenance and peer review Not commissioned; externally peer reviewed.

\section{REFERENCES}

1 Weiss SW, Goldbum JR. Benign tumors and tumor-like lesions of blood vessels. In: Enzinger and Weiss's Soft Tissue Tumors. 5th edn. St Louis: Mosby, 2008:636.

2 Bucci T, De Glullo F, Insabato L, et al. Cavernous hemangioma of the temporalis muscle: case report and review of literature. Acta Otorhinolaryngol 2008;28:83-6.

3 Nurliza I, Kenali MS, Sani A. Intramuscular haemangioma in the head and neck. Med J Malaysia 2007;62:409-10.

4 Song $\mathrm{BH}$, Youn $\mathrm{SH}$, Park EJ, et al. A case of sinusoidal hemangioma with lipoma. Ann Dermatol 2011;23:s250-3.

5 David EE, Rosalie E, Bernett LJ Jr, et al. Lever's histopathology of the skin. 9th edn. Lippincott Williams and Williams, 2005:1015.

6 Gamper TJ, Morgan RF. Vascular anomalies: hemangiomas. Plast Reconstr Surg 2002;110:572-85.

7 Engelstad BL, Gilula LA, Kyriaskos M. Ossifed skeletal muscle hemangioma: radiologic and pathologic features. Skeletal Radiol 1980;5:35-40.

8 Liston R. Case of erectile tumour in the popliteal space. Med Chir Trans 1843;26:120-32

9 Watson WL, McCarty WD. Blood and lymph vessel tumors: a report of 1056 cases. Surg Gynecol Obstet 1940;71:571-88.

10 Clemis JD, Briggs DR, Changus GW. Intramuscular hemangiomas in the head and neck. Can J Otolaryngol 1975;4:339-46.

11 Gregory KI, Gerald JB, Allen LS. Intramuscular hemangioma of the mentalis muscle. Oral Surg Oral Med Oral Pathol 1985;60:476-81.

12 Wolf GT, Daniel F, Krause CJ, et al. Intramuscular hemangiomas of the head and neck. Laryngoscope 1985;95:210-3.

13 Hoehn JG, Farrow GM, Devine KD. Invasive hemangiomas of the head and neck. Am J Surg 1970;120:495-8.

14 Odabasi AO, Metin KK, Mutlu C, et al. Intramuscular hemangioma of the masseter muscle. Eur Arch Otorhinolaryngol 1999;256:366-9.

15 Allen PW, Enzinger FM. Hemangioma of skeletal muscle: an analysis of 89 cases. Cancer 1972:29;8-22.

16 Calonje $E$, Fletcher $C D$. Sinusoidal hemangioma. A distinctive benign vascular neoplasm within the group cavernous hemangiomas. Am J Surg Pathol 1991;15:1130-5.

17 Kim EH, Kim YC, Lee SW. A case of polypoid hemangioma. Korean J Dermatol 2006:44:1016-17.

18 Pablo MD, Salil S, Meena C, et al. Masson's tumor: differential diagnosis of neck lump in children. Int J Pediatr Otolaryngol Extra 2006;1:196-9.

19 Kuo TT, Sayers CP, Rosai Juan. Masson's "vegetant intravascular hemangioendothelioma". A lesion often mistaken for angiosarcoma. Cancer 1976;38:1227-36.

Copyright 2015 BMJ Publishing Group. All rights reserved. For permission to reuse any of this content visit http://group.bmj.com/group/rights-licensing/permissions.

BMJ Case Report Fellows may re-use this article for personal use and teaching without any further permission.

Become a Fellow of BMJ Case Reports today and you can:

- Submit as many cases as you like

- Enjoy fast sympathetic peer review and rapid publication of accepted articles

- Access all the published articles

- Re-use any of the published material for personal use and teaching without further permission

For information on Institutional Fellowships contact consortiasales@bmjgroup.com

Visit casereports.bmj.com for more articles like this and to become a Fellow 